\title{
Metodología para el análisis de la fotografía histórica
}

\author{
Antonio Rodríguez de las Heras \\ Catedrático. Universidad Carlos III de Madrid \\ Methodology to analize the historic photography
}

\begin{abstract}
RESUMEN
Esta ponencia presenta unos principios metodológicos para el análisis de la fotografía histórica. El arranque para los fundamentos de esta metodología está en la interpretación de la fotografía como fragmento; como un fragmento de tiempo (instante) y de espacio (mirada). Desde esta concepción se puede levantar una lógica de estudio y unos procedimientos de análisis, así como abrir un campo de posibilidades de escritura con imágenes en un entorno multimedia.
\end{abstract}

PALABRAS CLAVES Fotografía, metodología, multimedia, Historia.

\section{ABSTRACT}

This paper presents some methodological principles for the analysis of historical photography. The starting point of the foundations of this methodology relies on the interpretation of the photograph as a fragment; a fragment of time (instant) and of space (look). From this conception it is possible to develop a logical framework for the study of historical photography along with some procedures of analysis, as well as to open a field of possibilities of writing through images within a multimedia context.

KEY WORDS

Photography, methodology, multimedia, History. 


\section{EL SOPORTE DIGITAL}

El cambio de soporte de la información ha abierto unas posibilidades muy sugerentes al uso de la imagen por el historiador. El paso del celuloide al soporte digital es mucho más que una simple sustitución del material sobre el que se recoge la imagen. Significa al menos tres fenómenos, que se están produciendo en estos momentos.

1. La migración. Se refiere a un desplazamiento masivo y acelerado del patrimonio fotográfico y cinematográfico recogido en soportes tradicionales al soporte digital. Con la migración se consigue un almacenamiento más seguro, pues se pueden hacer las copias de seguridad que se consideren oportunas; más compacto, por la densidad del soporte; y realizar la restauración, de necesitarla, de la imagen; asimismo, su organización en bases de datos es mucho más potente. Por otro lado, la migración no supone pérdida ni deterioro del soporte original. Pero además, con la migración digital se entra en la Red y entonces la imagen adquiere ubicuidad y potencialmente está disponible para acceder a ella desde cualquier lugar de la Red.

2. La capilaridad. La imagen creada por medios mecánicos, desde la fotografía del siglo XIX a la televisión del XX, ha dilatado la capacidad de ver del ser humano hasta entonces limitada a entornos muy reducidos: lo que permitían ver los cortos desplazamientos y aquello que se imaginaba a partir de lo que se contaba que había o que sucedía más allá del alcance de su presencia. Los medios de comunicación han potenciado extraordinariamente esta capacidad de ver. Pero incluso su extensión y densidad tienen un límite insuperable: no pueden estar en todos los lugares ni en todo los momentos, es decir, cubrir todos los sucesos. Y es entonces cuando la miniaturización y la Red producen, en asociación con los medios de comunicación, el fenómeno de la capilaridad. La captura de la imagen, sea fotografía o vídeo, está al alcance de la mano (nunca mejor dicho, pues el aparato cabe en una mano) de millones de personas en el mundo. Es ya raro que un suceso, por alejado o imprevisto, no tenga la presencia de al menos una persona con un artefacto digital para capturar sus imágenes. Y en un suceso multitudinario y anunciado no haya centenares, miles de puntos de vista de asistentes con sus cámaras capaces de mostrar múltiples instantes y perspectivas que los medios profesionales por sí solos no pueden conseguir. Lo importante es que esas imágenes no quedan encerradas en tales aparatos mínimos, sino que pasan a la Red y se hacen visibles para todo el mundo. Además, los medios de comunicación han entendido el nuevo fenómeno y se han asociado con los ciudadanos para que encuentren espacio donde difundir sus imágenes, y no sólo las excepcionales (desde iReport de la CNN hasta las fotografías de no profesionales con que se cierra actualmente algún noticiario o la información meteorológica). El resultado es una ampliación aún mayor de la capacidad de ver de las personas a través de la imagen digital, que se hace ubicua en este mundo en red. La abundancia y presencia de la imagen son asombrosas. 
3. La edición. El soporte digital para la imagen proporciona otra ventaja: se puede trabajar la imagen, fija o en movimiento, con la misma facilidad con que se trabaja la escritura en un procesador de textos. La imagen ha dejado de ser algo rígido, encerrada en su soporte de celuloide, de difícil manipulación y necesitada de unos medios complicados y no al alcance de cualquiera. La imagen se ha diluido en ceros y unos, de igual modo que lo ha hecho el sonido y la escritura, así que es de muy fácil manejo y necesita el mismo soporte material que el audio y el texto. Antes cada uno de ellos residía en soportes distintos (celuloide, papel, vinilo o cinta magnética) e inmiscibles y necesitaba artefactos también distintos. Ahora, igual que se escribe un texto y se publica en la Red se trabajan las imágenes y, también, pueden formar parte de una escritura multimedia compuesta de texto, sonido e imágenes.

Ante estos cambios, ¿cómo el historiador se va a mostrar indiferente? ¿Cómo va a considerar que no le atañen, que no le abren posibilidades para su trabajo? Con lo soportes anteriores era explicable que la relación con la imagen fuera fría, distante. Resultaba difícil llegar a ella, tratarla, incorporarla, reproducirla. A lo más, la fotografía se podía integrar en un texto o componer un libro de fotografías comentadas; la imagen en movimiento era intransferible desde su soporte al papel y, por tanto, debían permanecer separados imagen y texto: la imagen en un rollo de celuloide o en una casete de vídeo y el comentario en el papel de un libro. Pero en la actualidad el número creciente de fondos de imágenes digitalizadas disponibles en la Red, los medios tan asequibles y fáciles para trabajar con esas imágenes, y la posibilidad de publicaciones electrónicas multimedia, hacen difícilmente justificable que no se preste atención por parte del historiador.

Con unas posibilidades impensables hace unos años el historiador se enfrenta a unos fondos y a unos medios para tratarlos que exigen ya no sólo nuevas destrezas, que son muy fáciles de alcanzar, igual que disponer de los medios técnicos, sino, y eso es lo principal, unos métodos de trabajo para extraer toda la riqueza que guardan los fondos cada vez más numerosos y diversos que están disponibles. De ahí la oportunidad de esforzarse en explorar metodologías para el análisis de la fotografía histórica. Una fotografía que ya no está destinada a ser simple ilustración de un texto o a ser tratada sólo en un libro de fotografías. La pretensión de este artículo es mostrar uno de estos caminos propuestos para concretar una metodología de análisis. Antes, pues, de entrar en los estudios de las imágenes correspondientes a un período o tema concreto, conviene dedicar unas páginas a la reflexión y observación de cómo asaltar el estudio de cualquier colección de fotografías históricas.

\section{LA FOTOGRAFÍA COMO FRAGMENTO DE TIEMPO}

Esta propuesta metodológica arranca de la interpretación de la fotografía como fragmento de tiempo. El trabajo deductivo que vendrá a continuación parte 
de esta aceptación: un clic de la cámara corta el tiempo y entonces el resultado de esta operación, la fotografía, es un breve fragmento de tiempo. Si acordamos esto, tendremos que hacer todos los razonamientos a partir de la visión de la fotografía como fragmento de tiempo.

Así, como fragmento la fotografía contiene información parcial de una totalidad, por tanto algo que se presenta incompleto. Pero también como fragmento la fotografía es un rastro y un resto: un resto de aquello que queda de un tiempo incontenible. Ahora bien, si estamos ante un fragmento de un tiempo que pasa sin cesar, entonces tiene su lugar exacto en esa línea que deja el tiempo al pasar. Nos encontramos, pues, ante la tarea más evidente del estudio de la fotografía histórica: la datación; el trabajo de colocar el fragmento en su lugar en el tiempo.

\section{EL TESTIMONIO FOTOGRÁFICO}

La fotografía tiene su posición en la línea del tiempo, y a la vez ha tenido que realizarse en un determinado lugar en el espacio, por tanto, la fotografía se hace testimonio porque tiene que haber estado allí y entonces. Presencia, por consiguiente, de la fotografía en un lugar y en un momento. Veamos las fotografías que siguen:

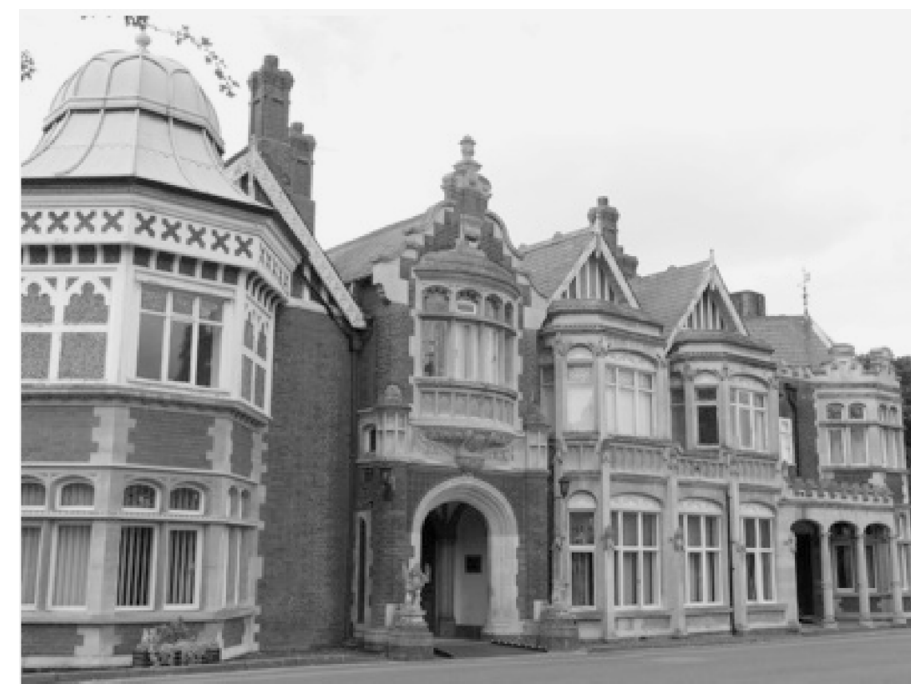

Está hecha en Bletchley, a unos $70 \mathrm{~km}$ al nordeste de Londres. En este edificio victoriano se ocultó durante la Segunda Guerra Mundial un numeroso equipo de investigadores, que desbordó la capacidad de la mansión y se instaló en barracones construidos por sus alrededores, con el objetivo de concebir una máquina que venciera a otra máquina; es decir, desarrollar el primer ordenador electrónico -Colos- 
sus- que tuviera la capacidad y velocidad suficientes para descifrar a tiempo los mensajes cifrados por la máquina Enigma del ejército alemán. Entre esos técnicos y científicos estaba la figura decisiva del matemático Alan Turing. Consiguieron su objetivo y también pasar desapercibidos para el espionaje enemigo. Esta fotografía recoge un edificio histórico, ahora convertido en museo, pero no es una fotografía histórica pues la realicé hace unos años. Contiene el allí, pero no el entonces.

Sin embargo, esta otra sí es histórica, pues se hizo en Bletchley en el momento en que se estaba desarrollando el proyecto Colossus.

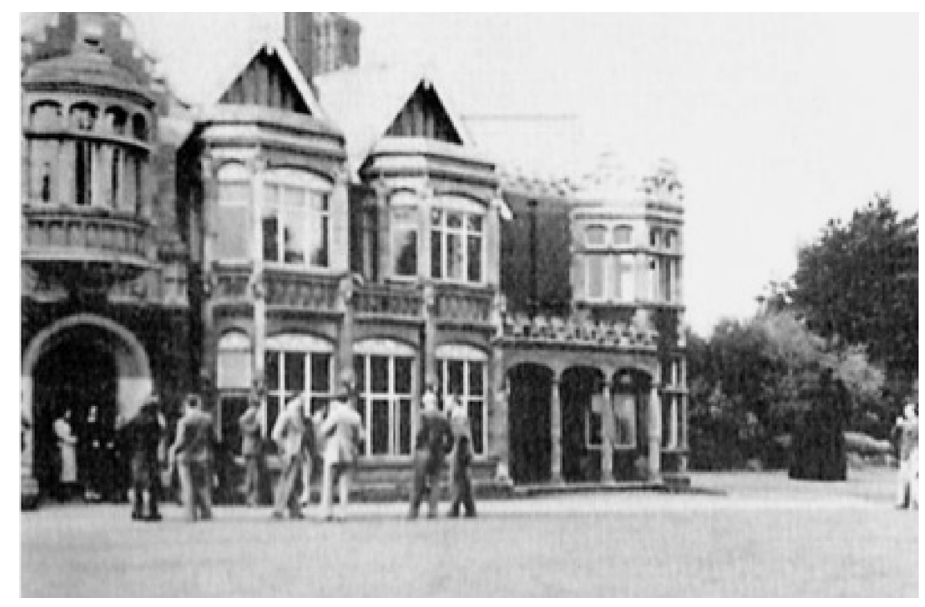

Naturalmente, la pertenencia al conjunto de fotografías históricas es un gradiente y no se debe resolver de forma binaria con un sí o un no. En este caso, si dentro de un tiempo el edificio desapareciera mi fotografía adquiriría un valor histórico que ahora no tiene.

En la siguiente, los dos personajes han pasado a la Historia: son los físicos Einstein y Szilard. La fotografía recoge la escena en que el húngaro Szilard visita a Einstein en el verano de 1939, para hablarle de los avances en fisión nuclear de los científicos alemanes y del riesgo de que este conocimiento posibilite la construcción de una fenomenal bomba, más inquietante aún por el ambiente de preguerra que se vive en esos momentos. De esa reunión saldrá la carta firmada por Einstein al presidente Roosevelt que dará paso al proyecto Manhattan. Esta fotografía se hace un tiempo después de la reunión. Para inmortalizarla se pide a los dos personajes que vuelvan a recrear la escena.

Y esta otra, tan difundida, del asalto al Palacio de Invierno durante la revolución rusa presenta unas sospechas en su realización que hacen pensar que no se pudo hacer en el momento en que los soviets, después de la salida de los cosacos, inician el asalto. El tiro de la cámara, cuando no hay en ese lugar una construcción que lo permita, así como que el suceso se produce de noche y en ese tiempo no 


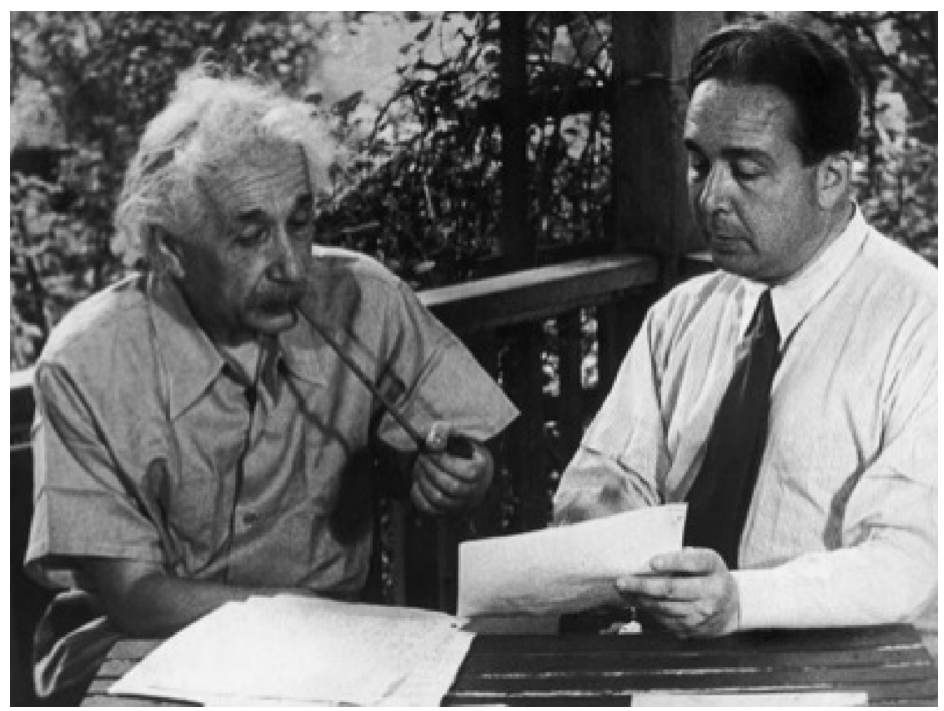

hay películas con esa sensibilidad, indican que no corresponde al momento. En efecto, es una representación años después interpretada por el Teatro de la sátira revolucionaria. El aquí, pero no el entonces. ${ }^{1}$

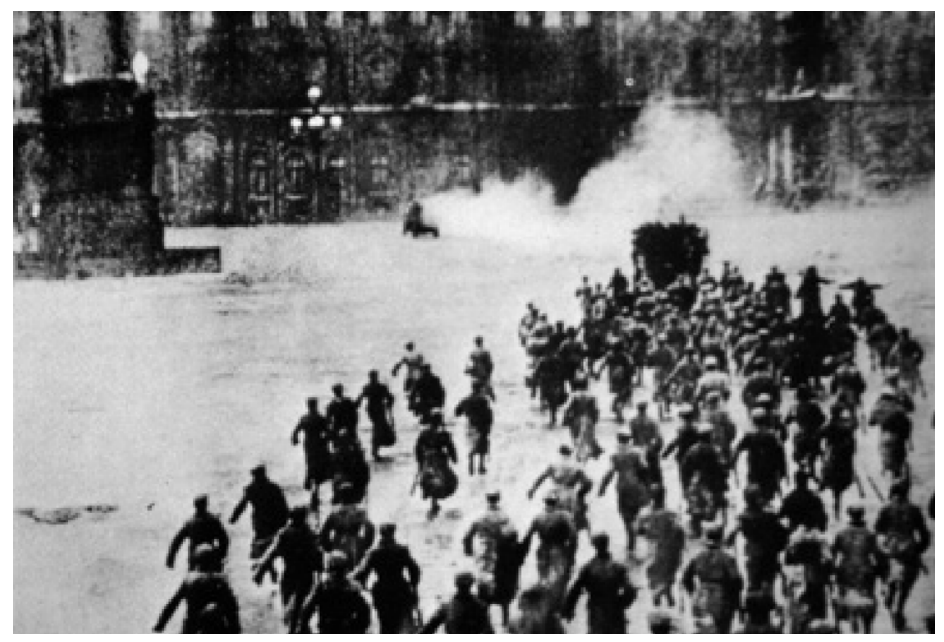

1 «Toute image, même mensongère, a sa vérité. Cette photographie représente bien un assaut contre le Palais d'Hiver. Nous sommes bien le 7 novembre. Et ce sont même sans doute, pour la plupart, de vrais soldats révolutionnaires qui courent sur l'esplanade. Mais la scène a eu lieu trois ans plus tard, en 1920, et en plein jour, lors d'une grande manifestation de rue organisée en commémoration des journées d'Octobre par le district militaire de Petrograd et avec la collaboration du théâtre d'agitation de la Comédie libre (Volnaïa Komedia), dit aussi ‘Théâtre de la satire révolutionnaire’ (Terevsat).» JAUBERT, A.: Le Commissariat aux archives. Les photos qui falsifient l'Histoire. Paris, Éditions Bernard Barrault, 1986, pág. 44. 


\section{LA INSTANTÁNEA}

Veamos otra consecuencia de la interpretación de la fotografía como fragmento de tiempo: corta el movimiento, y lo deja encerrado en una instantánea. Percibimos el movimiento según la capacidad de procesamiento de nuestro cerebro, de manera que quedan percepciones más allá de nuestras posibilidades de retención. Sólo vemos parte de lo que sucede ante nosotros, aunque lo estemos mirando muy atentamente. Pero la fotografía captura instantes que nuestro cerebro no ha podido procesar. Sirva la analogía de una sucesión de fotogramas para explicar el fenómeno: de un objeto de observación que se mueve, el cerebro procesa un conjunto de fotogramas, que constituyen lo que percibimos de esa trayectoria, pero entre fotograma y fotograma hay otros instantes que no se han procesado; en ocasiones una fotografía, que es un corte finísimo de ese movimiento, proporciona un fotograma que encaja entre dos de los procesados por nuestro cerebro; así que vemos con la fotografía algo que no hemos podido ver por atenta que fuera nuestra mirada.

Los testigos que estuvieron a la salida de Hitler de esta iglesia, no percibieron lo que la instantánea del fotógrafo oficial del mandatario retuvo al cortar el movimiento: la coincidencia de la cruz sobre la cabeza inclinada del Führer. No es de extrañar que fuese censurada. ${ }^{2}$

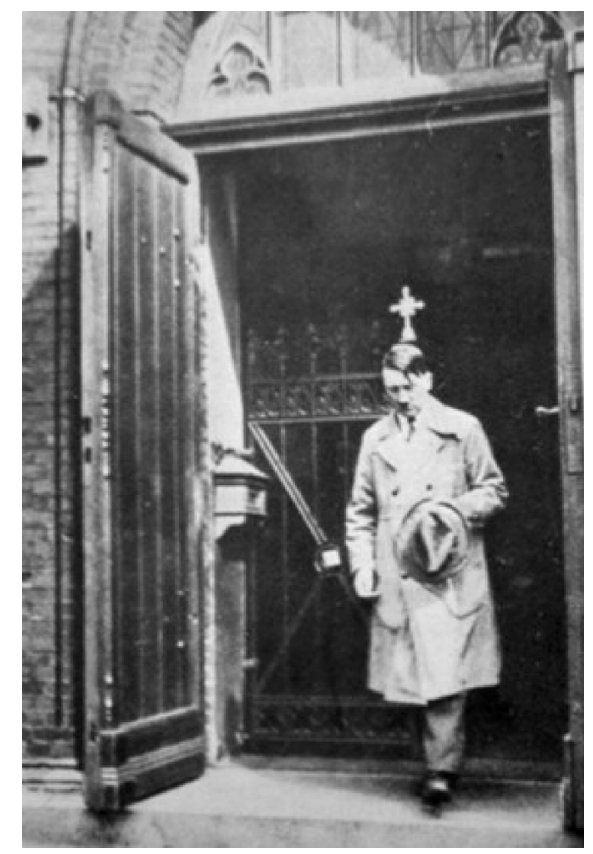

${ }^{2}$ Está fotografía se recoge en las dos primera ediciones (1932 y 1934) del libro de Heinrich Hoffmann, Hitler Wie ihn Keiner Kennt. Luego este libro será retirado de la circulación y su centenar de fotografías no se volverá a publicar hasta después de la Segunda Guerra Mundial. 
El aparente cruce de miradas entre el maniquí y la transeúnte no se habrá percibido por las personas que estuvieran en ese momento en la tienda y mirando al exterior.

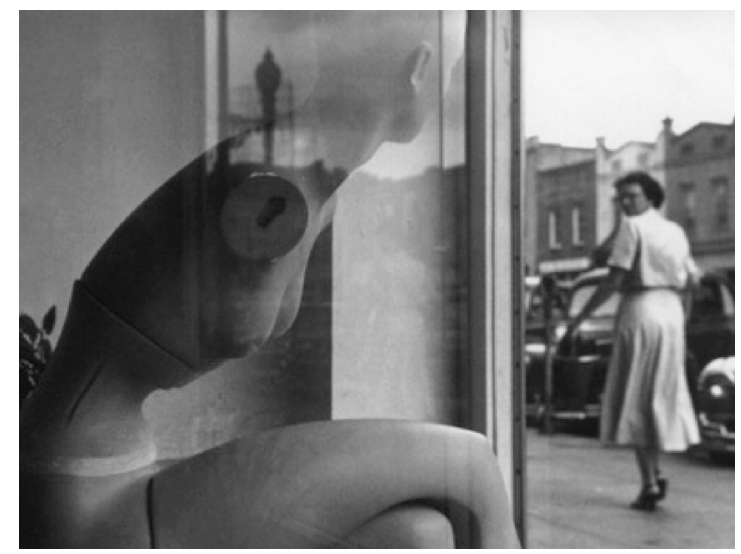

De igual modo nos sirve esta otra fotografía que recoge los gestos de Lloyd George y Churchill a la entrada del Parlamento, en 1910.

«A striking photograph can be more eloquent than prose -and sometimes tell us more about character. There was a photograph taken early in the last century of David Lloyd George and Winston Churchill as relatively young men walking towards Parliament. Both are wearing silk top hats and smart dark clothes. Churchill carries a silver-topped walking stick. The photograph not only conveys the character of both men, but offers an impression of Parliament in those days. $\gg^{3}$

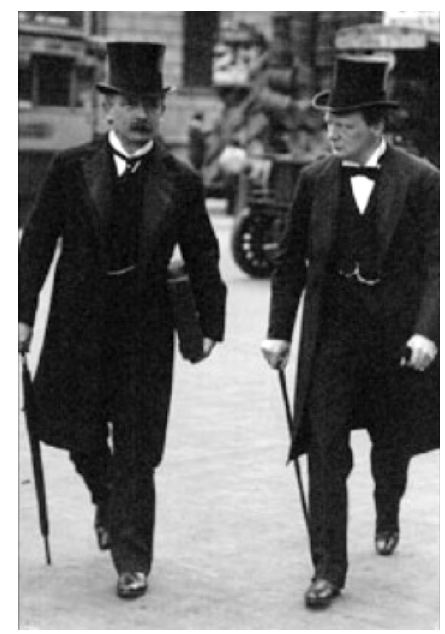

3 HARGREAVES, R. y DEEDES, B.: Daily Encounters. Photographs from Fleet Street. London, National Portrait Gallery, 2007, pág. 12. 


\section{EL PROCESO}

Estamos interpretando la fotografía como un fragmento de tiempo. El tiempo fluye inconteniblemente y el clic de la cámara obtiene un pequeño fragmento que es la fotografía. Ese pequeño fragmento tiene su lugar en la línea del tiempo (datación), y de igual modo tiene un lugar en el espacio porque la cámara ha debido estar situada en ese momento delante de la escena que ha capturado. Así que la fotografía tiene un allí y un entonces, lo que la hace convertirse en testigo de lo que ya ha pasado. Además, al ser un fragmento tan minúsculo (una décima, una centésima de segundo), aunque cargado de información, puede ser que aporte una visión que el cerebro de una persona in situ no capta, pues ya hemos señalado que el procesamiento de la visión del entorno por el cerebro es como una sucesión de fotogramas, y una fotografía puede entonces encajar entre dos fotogramas y de esa manera presentar algo que no se ha percibido. La fotografía, por consiguiente, a pesar de que es un breve fragmento de tiempo, está cargada de información, y en consecuencia un primer trabajo con ella consiste en extraer toda la información que contiene ese fragmento.

Pero como fragmento también hay otra posibilidad de trabajar con él, y es buscar su ajuste con otros fragmentos. A diferencia de dos fragmentos de cerámica, por ejemplo, que para que ajusten, si no son contiguos, se necesita hallar todos los demás fragmentos que hay entre ellos dos, en los fragmentos de tiempo no es necesario. Se pueden unir dos fragmentos separados en la línea del tiempo y obtener como resultado un proceso. Es una operación semejante a la de levantar un arco temporal: los dos fragmentos son los pilares y el proceso es el arco; hay entonces una continuidad, a pesar de que hay más vacío que piedra. Con varios fragmentos, por tanto, se construye un puente, que es un continuo, y en el que hay más vanos que material.

Estas dos fotografías expresan de manera rotunda que uno más uno no son dos instantes sino un proceso. Son fotografías de Robert Capa en los últimos días de la Segunda Guerra Mundial sobre territorio europeo. Si observamos la primera de ellas, tenemos la percepción de un soldado muerto; pero si vemos la sucesión de las dos la interpretación cambia y asistimos ya no a la visión de un muerto sino de un agonizante. Con dos instantes se expresa un proceso, el de la agonía. No hay movimiento, pero sí proceso.

Así que, el trabajo con la fotografía no se reduce a extraer la información que contiene el fragmento, sino a realizar posibles combinaciones con otros fragmentos para descubrir procesos significativos. 

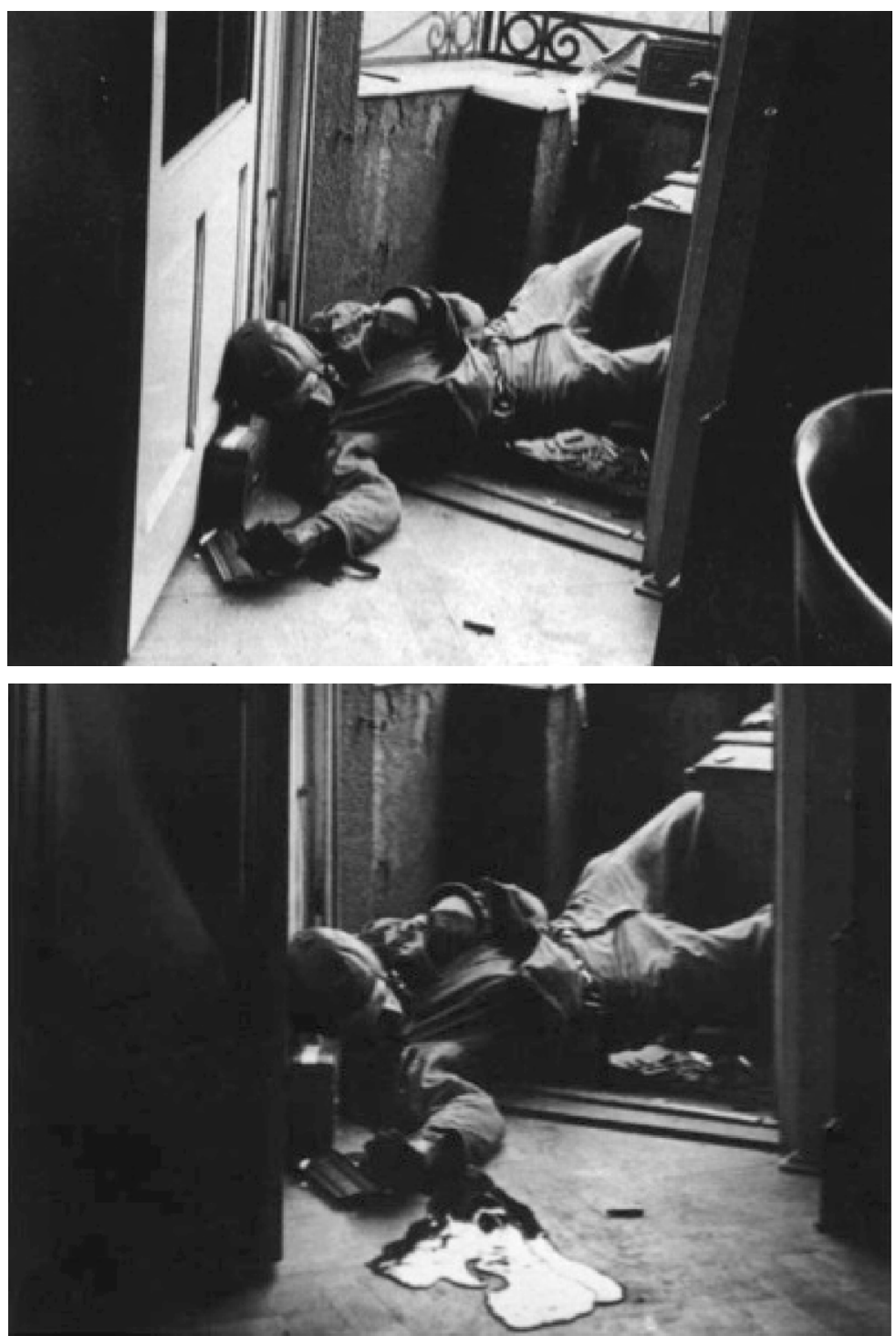

\section{LA MIRADA}

Todo se mueve y transcurre a nuestro alrededor, lo que hace que estemos sumergidos en sensaciones de que el tiempo fluye sin cesar. ¿Cómo intentamos retener ese paso imparable? Con la mirada. Mirar es pretender que las cosas no se las lleve el tiempo. Un objeto pasa ante nuestra vista, así que lo vemos; pero si nos fijamos en él, es decir, lo miramos y seguimos su desplazamiento, entonces esta- 
mos procurando que el paso no sea tan fugaz, permanezca ante nosotros, lo retengamos con la mirada. Pero a la vez, al mirar centramos la atención en una parte de lo que vemos, por tanto con la mirada fragmentamos el espacio: una parte queda abarcada por nuestra mirada y otra excluida.

La fotografía, como toda herramienta, amplifica una función natural; en este caso la de la mirada. Retiene más intensa y duraderamente lo que se mira, pero también fragmenta más radicalmente el espacio con un dentro y un fuera de la mirada más marcados. Con la mirada natural, se fija la atención en una parte de lo que se ve, y lo que queda fuera de la mirada se percibe difusamente con la visión periférica. En la de la mirada amplificada por el artefacto fotográfico, el corte es más radical: queda bien retenido lo que se mira y excluido totalmente el resto. Así que, si el complemento de la mirada natural es la visión periférica, el de la mirada mediada por la máquina tiene que ser el contexto. En el estudio de la fotografía, al ser también además de un fragmento de tiempo un fragmento de espacio, el análisis debe aportar aquello que rodea la fotografía pero que no aparece en ella. Si nos moviéramos por el mundo sólo con la mirada, sin visión periférica, nuestros desplazamientos y actuaciones estarían cargados de errores y riesgos. Igual sucede con la fotografía por ser mirada: sin contexto su análisis está amenazado de errores. En la fotografía histórica el análisis del historiador es imprescindible.

Nos podemos preguntar si la mirada, si la fotografía al ser fragmentos, ¿entonces trocean el mundo y lo desmenuzan? ¿O, al contrario, lo ordenan? Estas fotografías que siguen pueden dar la respuesta.

Si la mirada es por encima del muro, lo que vemos en este momento es a una pareja de ancianos acercándose con un ramo de flores.

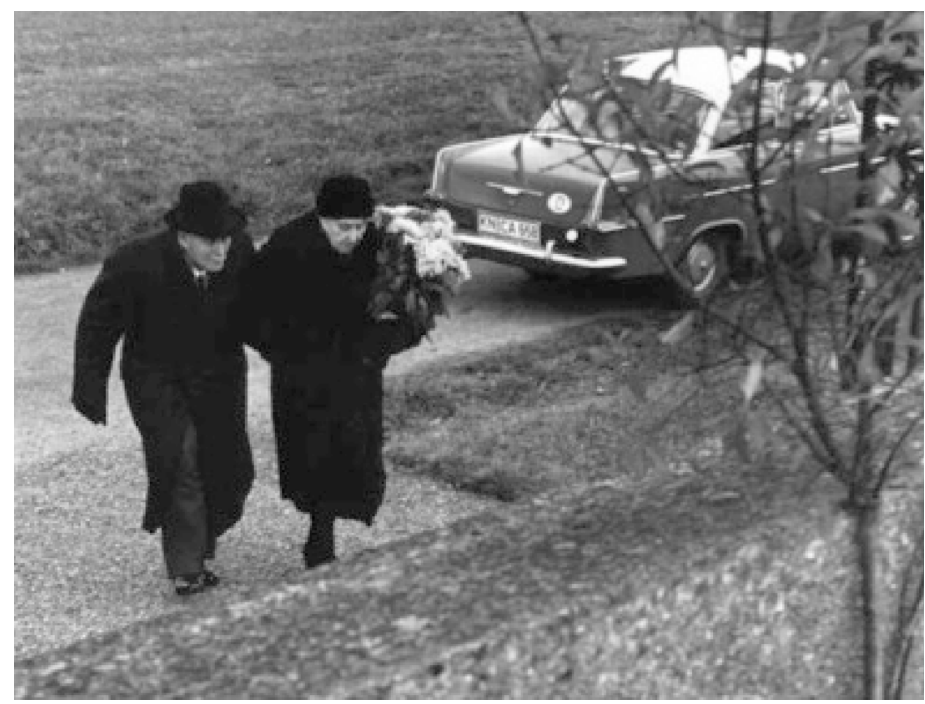


$\mathrm{Si}$, en cambio, miramos por debajo del borde del muro, lo que encontramos es una lápida con la fotografía de un militar del ejército alemán fallecido durante la Segunda Guerra Mundial.

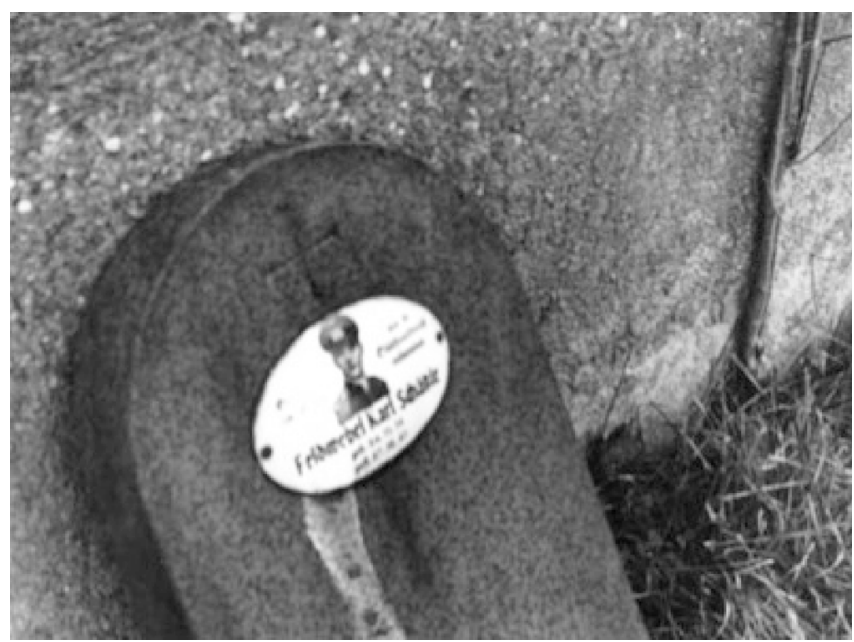

Pero si la mirada se concentra menos, otra lectura se puede hacer: unos padres que siguen llevando flores a su hijo muerto tempranamente por la guerra.

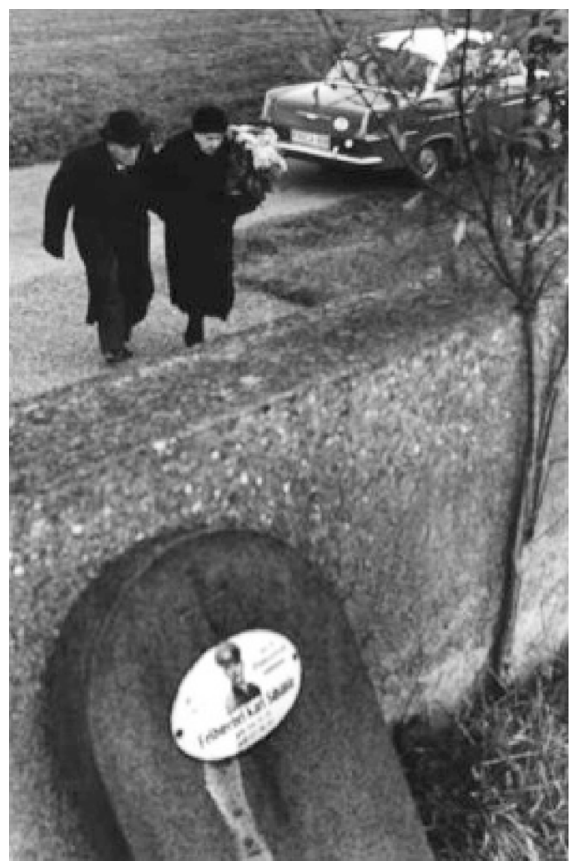


La siguiente fotografía es la de una joven china que nos mira.

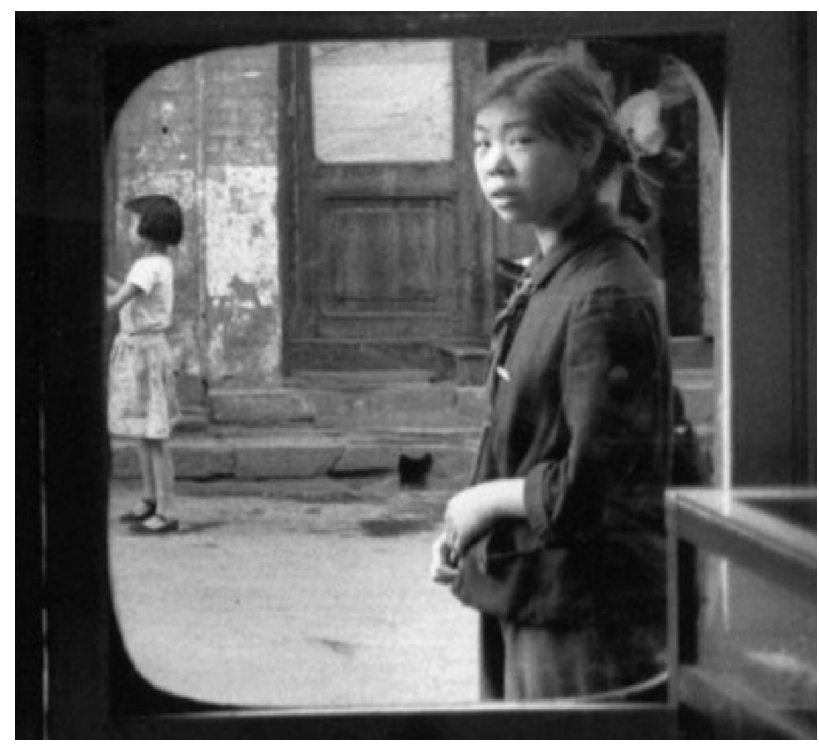

Y esta la de unas personas mayores a la puerta de su casa.

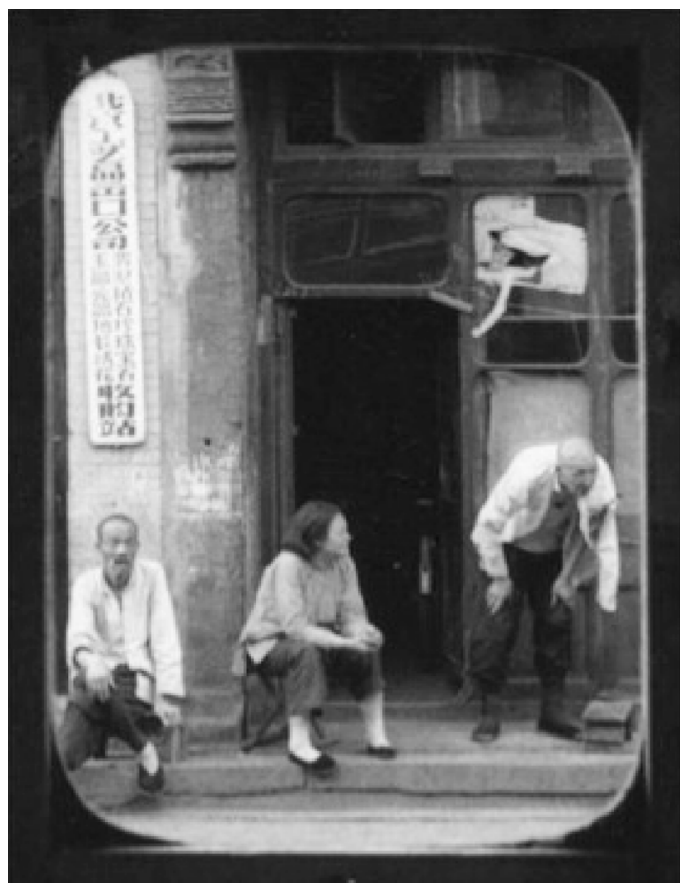


Y ahora, unos niños en la calle.

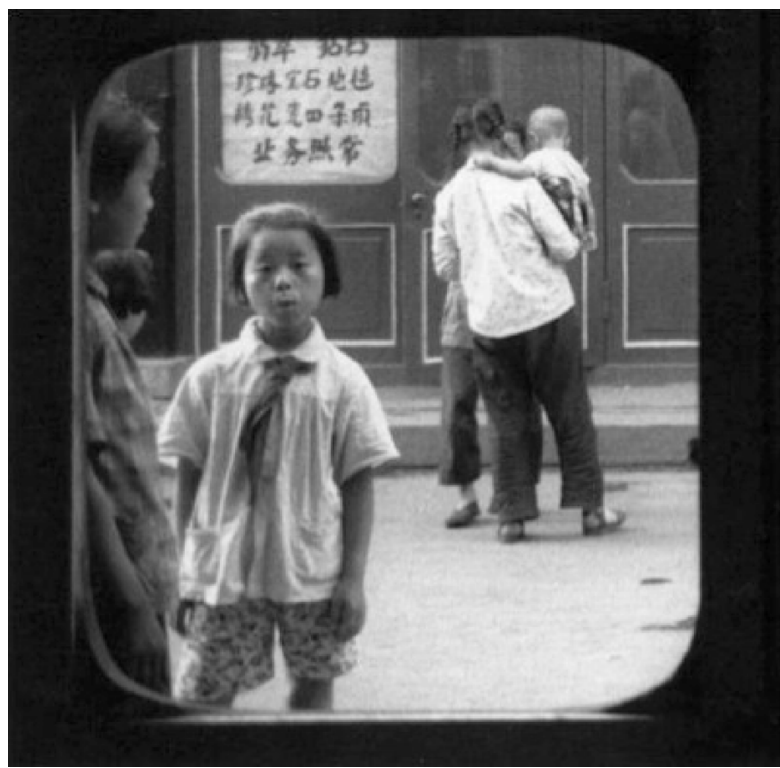

Pero la fotografía completa es la de una calle vista tras los cristales de una tienda. Los marcos de esos cristales fragmentan la escena como lo hace nuestra mirada.

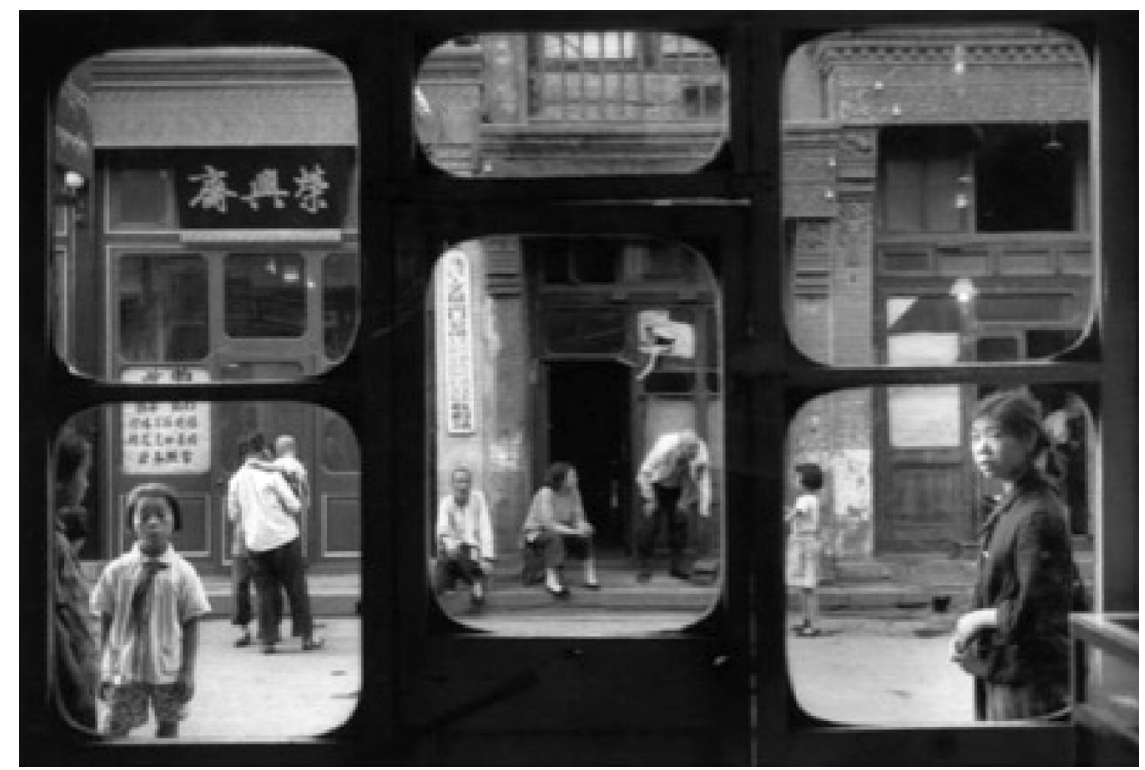


Si la mirada ordena el mundo y la fotografía, por ser también mirada, lo narra (por tanto, lo ordena) de una determinada manera, hay que desprenderse de cualquier ingenua pretensión de objetividad de la mirada automática, la que resulta de un clic de la cámara. No hay objetividad (ni necesidad de ella) en la mirada ni en la fotografía. Si el mundo se hace polifacético por las distintas miradas que lo observan simultáneamente, todas ellas son aportaciones válidas del mundo. La objetividad sólo haría empobrecer ese mundo reduciéndolo a un único plano.

\section{CUATRO LÍNEAS DE TRABAJO}

La interpretación de la fotografía como fragmento, como fragmento de tiempo (instante) y de espacio (mirada), posibilita una analogía y hablar de la arqueología de la fotografía histórica. Igual que un fragmento arqueológico, la fotografía es susceptible de ser estudiada dentro de estas cuatro coordenadas.

Todo fragmento, por diminuto que sea, es una fracción de un todo pero contiene información. Por tanto, una primera tarea es extraer esa información a través de la observación y el análisis. Y también, al ser un fragmento de tiempo, su colocación en el lugar que le corresponde, es decir, la datación, es imprescindible. Un profundo análisis de los detalles de una fotografía hace aflorar mucha información que a una persona no experta se le escapa. Lo mismo sucede con un pequeño resto arqueológico en manos de un experto.

Como la fotografía ha tenido que estar allí y entonces se convierte en testigo de algo sucedido, algo que ha pasado y que deja un rastro y un resto en la fotografía. Es sólo una fracción, pero como el testigo de un terreno (especie de hito de tierra que se deja a trechos en las excavaciones y que permite marcar el nivel del terreno removido) ayuda a la reconstrucción de lo que ya no está.

El allí y el entonces de la fotografía histórica significa presencia. El instante fosilizado de una fotografía aporta el testimonio de haber estado presente en un suceso. Pero con el paso del tiempo ese presente deja de serlo y se reduce al instante fosilizado por las reacciones químicas de la película. $Y$ ese instante es el que nos llega a través de la fotografía. Para que adquiera de nuevo presencia, no basta colocar ese instante en su lugar en la línea del tiempo (datación), como si fuera tan solo un punto de esa línea cronológica. La datación es necesaria, pero no suficiente. La diferencia entre el instante y el presente, es que el instante es un punto infinitesimal y el presente es el instante dilatado por la tracción en sentidos opuestos del pasado y del futuro. Por consiguiente, el instante fotográfico se convierte en presencia, en testigo de un tiempo pasado si incorporamos a ese instante su pasado y su futuro, su antes y su después, si entra en un proceso narrativo.

Por ser también, además de un fragmento de tiempo, un fragmento de espacio, es decir, una mirada, hay que añadir para que adquiera toda su significación lo que no se recoge dentro del marco de esa mirada, y que es el equivalente, como ya se 
ha señalado, de la visión periférica en la mirada natural. Hay, por tanto, que incorporar el contexto, y eso es también labor del historiador.

El rigor de la extracción de la información así como de la contextualización debe ser igual al que se marca un arqueólogo ante cualquier pieza.

Otra dimensión que hay que tener en cuenta para la explotación de la fotografía como fragmento es la de su ajuste con otra u otras fotografías para construir los arcos temporales de los procesos. Reunir dos o más fragmentos de tiempo para que de su encaje aparezca un proceso, un cambio significativo sostenido sólo por unos instantes. Tal proceso se puede haber gestado a lo largo de un tiempo más o menos extenso, pero son suficientes dos instantes en sus extremos para sustentar todo el arco del proceso. La información contenida en una fotografía se puede acrecentar por la conexión con otra u otras fotografías; la información que emerge no está contenida en ninguna de las fotografías, sino en el ajuste entre ellas. Esta exploración por un puzzle sin límite en busca de encuentros significativos es igualmente tarea del historiador.

Por último, y también como resultado de ver las fotografías como fragmentos, otra línea de trabajo con ellas es la de la asociación, ya no para obtener procesos, sino otros resultados igualmente significativos. Del mismo modo que la memoria trabaja por asociación y encuentra detalles sutiles en recuerdos bien distintos para enlazarlos intensamente, así se pueden asociar imágenes alejadas en tiempo, espacio e incluso motivo para que emerja una información no contenida en ninguna de ellas, sino en su reunión.

Seguimos consecuentes con esta analogía que nos permite hablar de la arqueología de la fotografía histórica y que arranca de la interpretación inicial de la fotografía como fragmento de tiempo y de espacio. Una pieza arqueológica proporciona información al investigador, pero su destino final no tiene que ser necesariamente un sótano como depósito. Tiene otro valor de representación y de comunicación. Por eso pasa a formar parte de un discurso en el espacio de un museo o exposición. Pues bien, de igual manera las fotografías históricas proporcionan información al estudioso, pero también pueden y deben entrar en un discurso. Aquí no es la sala del museo sino el espacio multimedia que ofrece la tecnología digital. Como ya hemos señalado al comienzo de este artículo, el soporte digital posibilita una escritura multimedia de imágenes, sonidos y palabras, una asociación de la imagen y el texto como no se había podido conseguir en los soportes anteriores; un espacio privilegiado en donde componer discursos combinando la imagen, el texto, y si es necesario, el sonido. Además, la difusión de las producciones digitales tiene una potencia, tanto en extensión como en rapidez, inimaginables cuando los soportes eran sólo el papel y el celuloide. ${ }^{4}$

4 Una muestra personal de este uso de la escritura multimedia para asociar imagen, texto y audio se puede ver en Imagen y violencia,

http://web.mac.com/rodriguezdelasheras/imagenypalabra/ARH2.html 
Un prometedor campo de estudio y de comunicación propio del historiador, irrenunciable e intransferible, y que, por tanto, debe prepararse (y formar a los jóvenes historiadores) para extraer todas las posibilidades que guarda.

y en Historia y Fotografía.

http://web.me.com/rodriguezdelasheras/hyf/b.html

La organización que se puede hacer de un corpus fotográfico histórico, como uno referente a San Petersburgo antes de la Revolución, se describe en el vídeo

http://homer.uc3m.es/audiovisuales/Cursos/MeDEA/2005/SanPetersburgo.wmv

También en Imagen y Memoria de la UGT, vídeo resumen del trabajo multimedia, accesible desde:

http://homer.uc3m.es/audiovisuales/Cursos/MeDEA/2005/UGT.wmv

Y en el texto «La fotografía digital» en Imatge i Recerca. V Jornades Antoni Varés, Girona, 1998, págs. 95 a 126. 